\title{
Reconstruction of traumatic and non-traumatic lower extremity defects with local or free flaps
}

\author{
Eva Györi (D) Anna Fast · Annika Resch · Thomas Rath · Christine Radtke
}

Received: 8 March 2021 / Accepted: 15 March 2021 / Published online: 22 April 2021

(C) The Author(s) 2021

\begin{abstract}
Summary
Background Despite continuous surgical advances, reconstruction of complex lower extremity wounds remains challenging. The indication of local flaps or microsurgical free tissue transfer depends on the anatomical location and size of the defect, as well as the comorbidities and general condition of the patient. In this study, local and free flap reconstruction of distal lower extremity defects was assessed, and postoperative complications and limb salvage were analyzed.

Methods A total of 34 patients were included in this retrospective study. Distal lower extremity defects were of traumatic (29\%) and non-traumatic (71\%) etiologies. Patient characteristics, flap selection, postoperative complications, and limb preservation within the first 12 months were assessed and compared by reconstructive treatment concept. Statistical analysis included parametric and non-parametric tests. The two-sided alpha was set at $5 \%$ for all statistical tests. Results While 21 patients were treated with local flaps, 13 patients underwent microsurgical free flap reconstruction. The most common comorbidities were peripheral vascular disease and diabetes. Local flaps included the gastrocnemius muscle flap, soleus flap, sural flap, and plantaris medialis flap. The most commonly used free flaps for soft tissue reconstruction were latissimus dorsi and gracilis muscle flaps. The overall lower extremity preservation rate was 94.1\%. There was one case of below-knee amputation 1 month after free flap reconstruction, and one
\end{abstract}

E. Györi, MD, PhD $(\bowtie) \cdot A$. Fast · A. Resch, MD .

Ao. Prof. T. Rath, MD - Univ. Prof. C. Radtke, MD, MBA, FEBOPRAS

Department of Plastic and Reconstructive Surgery, Medical University of Vienna, Spitalgasse 23, 1090 Vienna, Austria eva.gyoeri@meduniwien.ac.at case of first-ray amputation of the foot after local flap coverage.

Conclusion Reconstruction of lower extremity defects can be achieved by local or free flap reconstruction. Flap selection is influenced by anatomical location, defect size, and patient factors.

Keywords Soft tissue reconstruction - Microvascular tissue transfer · Pedicled flap · Limb salvage .

Extremity preservation

\section{Main novel aspects}

1. Patient characteristics, such as age and etiologies of the lower extremity defects, did not significantly differ between treatment groups.

2. Successful limb salvage was achieved in over $90 \%$ after local and free flap soft tissue reconstruction.

\section{Introduction}

Reconstruction of the distal lower extremity remains challenging despite continuous advances in surgical techniques. Limb preservation, early ambulation, and optimized functional outcomes are therapeutic goals that often require a multistep surgical approach in patients presenting with complex lower extremity defects with exposed vital structures or bones [1]. The mechanisms leading to extensive lower extremity wounds are diverse, including trauma, oncological resection, peripheral arterial disease, diabetes, and chronic venous stasis [2]. The size and anatomical location, as well as the comorbidities and acute state of the patient, are considered in the selection of reconstructive concept [2]. Large, complex defects in the distal third of the leg with exposed skeletal structures, tendons, nerves, and vessels often require microsurgical free flap reconstruction. Local and re- 
Table 1 Etiologies of lower extremity defects

\begin{tabular}{l|l|l|}
\hline Etiology of defect & Number of patients & Percent \\
\hline Trauma & 10 & 29.4 \\
\hline Peripheral vascular disease & 9 & 26.5 \\
\hline Diabetes & 6 & 17.6 \\
\hline Postoperative & 3 & 8.8 \\
\hline Vasculitis & 2 & 5.9 \\
\hline Infection & 2 & 5.9 \\
\hline Polyneuropathy & 1 & 2.9 \\
\hline Tumor & 1 & 2.9 \\
\hline Total & 34 & 100 \\
\hline
\end{tabular}

gional flaps are used for the reconstruction of small to moderately size defects. Local flaps provide similar tissue characteristics, thickness, and weight-bearing capacity to the reconstructed areas [3]. Microsurgical free flap reconstruction is widely established in traumatic and non-traumatic lower extremity defects and was proven to be safe in patients of advanced age, although the patients suitability to undergo extended surgeries needs to be explored [4-6]. The timing of reconstructive surgery is influenced by multiple factors including the patients' general state and the contamination of the wound; however, in traumatic defects, early free tissue transfer was associated with less complications than delayed reconstruction [7]. Postoperative complications and long-term limb salvage need to be considered when evaluating complex lower extremity reconstructions [2]. Lower extremity preservation leads to improved survival rates in multimorbid patients suffering from non-traumatic defects [8]. If the patient is stable enough for reconstruction, limb salvage and functional restoration should be the treatment goal [1]. The challenges of foot and distal lower extremity reconstruction are not only coverage of soft tissue and bone defects, but also the restoration of motor function and sensation, as well as achievement of acceptable aesthetic results in terms of contour and tissue texture [9]. Flap selection is driven by the extent of tissue damage, the anatomical subunit that requires reconstruction, the vascularity of the leg, and comorbidities of the patient [10]. Local flap reconstructions, if available and suitable for the defect size, have been associated with less reoperations and shorter hospitalization times compared to free flap reconstruction [11].

The aim of this retrospective study was to assess distal lower extremity reconstruction with local flaps and microsurgical free tissue transfer. Postoperative complications and limb preservation rates were analyzed and compared by reconstructive concept.

\section{Materials and methods}

The local ethics committee granted approval of this retrospective analysis (ethics approval number 1726/2019). All data assessed for the current study
Table 2 Anatomical locations of lower extremity defects

\begin{tabular}{|l|l|l|}
\hline Defect location & Number of patients & Percent \\
\hline Knee & 2 & 5.9 \\
\hline Proximal $1 / 3$ of the tibia & 4 & 11.8 \\
\hline Middle $1 / 3$ of the tibia & 3 & 8.8 \\
\hline Distal $1 / 3$ of the tibia & 2 & 5.9 \\
\hline Ankle & 1 & 2.9 \\
\hline Lateral malleolus & 4 & 11.8 \\
\hline Medial malleolus & 1 & 2.9 \\
\hline Achilles' tendon & 2 & 5.9 \\
\hline Heel & 3 & 8.8 \\
\hline Lateral forefoot & 1 & 2.9 \\
\hline Plantar surface of the foot & 5 & 14.7 \\
\hline Dorsum of the foot & 2 & 5.9 \\
\hline Great toe & 1 & 2.9 \\
\hline Total & 34 & 100 \\
\hline
\end{tabular}

were obtained from the patients' charts and operative reports.

\section{Inclusion and exclusion criteria}

Patients undergoing lower extremity reconstruction with local or free flaps were included in this study. Other inclusion criteria were age over 18 years, defects distal to the knee level, and postoperative followup times exceeding 12 months. Patients with proximal lower extremity defects were excluded from this study. Incomplete documentation or primary reconstruction at a different center also resulted in exclusion from the study.

\section{Patient population}

Thirty-four patients, 24 male $(70.6 \%)$ and 10 female (29.4\%), were included in this retrospective study. The most common causes for lower extremity defects were traumatic injuries in 10 cases $(29.4 \%)$. Other causes of defects of the lower extremity included peripheral vascular disease in 8 cases $(23.5 \%)$ and diabetes in 6 cases (17.6\%). Three patients $(8.8 \%)$ presented postoperative lower extremity defects that required reconstruction. Defects were caused by bacterial infection and vasculitis in 2 cases each. All causes of lower extremity defects are summarized in Table 1 . The included patients were analyzed in two groups: local flap and free flap reconstruction.

The selection of reconstructive concepts was determined by both patient factors and anatomical location of the defect, which are described in Table 2.

The reconstructive concept, flap type, postoperative complications, and revision surgeries were assessed in this retrospective study. All included patients were followed up for at least 12 months after reconstructive surgery. The lower extremity salvage rate und subsequent amputations were assessed. 
Table 3 Patient characteristics grouped by local or free flap reconstruction

\begin{tabular}{|c|c|c|}
\hline & Local flap & Free flap \\
\hline \multirow[t]{2}{*}{ Gender } & Female: 6 & Female: 4 \\
\hline & Male: 15 & Male: 9 \\
\hline Age & $\begin{array}{l}62.4 \text { years (SD 14.8, range: } 23 \\
\text { to } 83 \text { ) }\end{array}$ & $\begin{array}{l}54.9 \text { years (SD } 11.9 \text {, range: } 35 \\
\text { to } 70 \text { ) }\end{array}$ \\
\hline \multirow{4}{*}{$\begin{array}{l}\text { Comor- } \\
\text { bidities }\end{array}$} & Diabetes: 4 & Diabetes: 3 \\
\hline & Peripheral vascular disease: 2 & Vasculitis: 1 \\
\hline & Paraplegia: 2 & - \\
\hline & Polyneuropathy: 1 & - \\
\hline
\end{tabular}

\section{Statistical analysis}

SPSS version 24.0 (IBM SPSS Statistics $\odot$, Armonk, NY, USA) was used for statistical analysis. Descriptive statistics were performed for all parameters and were reported as mean, standard deviation (SD), and range for metric parameters. Statistical analysis included chi-squared tests for categorical variables, and $t$-tests for continuous variables. The two-sided alpha was set at $5 \%$ for all statistical tests.

\section{Results}

Patients included in this study were subdivided by treatment concepts. The first group included patients treated with local tissue transfer and the second group patients with microsurgical free flap reconstructions.

\section{Reconstructive concepts for lower extremity defects}

The lower extremity defects were reconstructed with local tissue transfer in 21 patients, which included 15 male and 6 female patients. The mean age in the local flap group was 62.4 years (SD 14.8, range 23 to 83 years). Microsurgical free tissue transfers were performed in 13 patients ( 9 male, 4 female), with a mean age of 54.9 years (SD 11.9, range 35 to 70 years). Statistically, there was no significant age difference between patients treated with free or local flap reconstruction $(p=0.113)$. Differences in gender distribution between the groups did not reach statistical significance either $(p=0.891)$.

Comorbidities were assessed in all patients (Table 3). The most common comorbidity in both groups was diabetes, in $19 \%$ of patients treated with local flaps and $23 \%$ of free flap patients.

The anatomical location of the lower extremity defects implicated the selection of therapeutic concept next to the patients' age and comorbidities. The flaptype selection and defect locations are displayed in Tables 4 and 5 .

Fig. 1 demonstrates a case example of a patient presenting with a defect over the lateral malleolus who underwent local flap reconstruction with a dorsalis pedis flap. The donor site was covered with a splitthickness skin graft.
Table 4 Local flap reconstruction by anatomical location

\begin{tabular}{l|l|l|}
\hline Defect location & Local flap & $n$ \\
\hline Knee & Medial gastrocnemius muscle flap & 1 \\
\hline Proximal $1 / 3$ of calf & Soleus flap & 1 \\
\cline { 2 - 3 } & Medial gastrocnemius muscle flap & 3 \\
\hline Medial $1 / 3$ of tibia & Soleus flap & 3 \\
\hline Distal tibia & Sural flap & 1 \\
\hline Heel & Sural flap & 1 \\
\hline Ankle & Plantaris medialis flap & 1 \\
\hline Achilles' tendon & Sural flap & 1 \\
\hline Medial malleolus & Local perforator flap & 1 \\
\hline Lateral foot & Plantaris medialis flap & 1 \\
\hline Plantar foot & Plantaris medialis flap & 1 \\
\hline Great toe & Local perforator flap & 2 \\
\hline & Local perforator flap & 1 \\
\hline
\end{tabular}

\section{Postoperative complications after lower extremity reconstruction}

The majority of patients healed without any postoperative complications (67.6\%; Fig. 2). Overall, the most common postoperative complication requiring revision surgery was delayed wound healing, affecting $17.6 \%$ of all patients (local flap: 19\%; free flap: 15\%). In the group of patients reconstructed with free tissue transfer, one case of flap necrosis occurred (Table 6). There was no significant difference in the postoperative complications rate $(p=0.694)$ between local and free flap reconstruction. Operative revisions were required in 5 patients $(23.8 \%)$ reconstructed with local flaps. Procedures included 3 (14.3\%) split-thickness skin grafts in patients with delayed wound healing, $1(4.8 \%)$ secondary wound revision and closure, and $1(4.8 \%)$ hematoma removal. In patients undergoing free flap reconstruction, 1 (7.7\%) anastomosis revision on the sixth postoperative day and $4(30.7 \%)$ splitthickness skin grafts were required as revision surgeries.

There was no statistical difference in mean length of hospital stay between the two groups. The duration of stay was 33.5 days (SD 41.6 days) in patients treated with local flaps and 34.8 days (SD 31.6 days) in patients who underwent free tissue transfer.

Lower extremity preservation was assessed within 12 months of postoperative follow-up. The overall lower extremity preservation rate was $94.1 \%$. There was one case of below-knee amputation 1 month after free flap reconstruction because of partial flap necrosis in a patient with preexisting vasculitis. In the group treated with local flap reconstruction, one patient underwent amputation of the first ray of the foot 12 months after the initial reconstruction because of osteomyelitis and local gangrene. Analysis of the influence of age, gender, or comorbidities did not reveal any statistically significant differences. 
Table 5 Free flap reconstruction by anatomical location

\begin{tabular}{lll}
\hline Defect location & Free flap & $n$ \\
\hline Knee & Latissimus dorsi & 1 \\
\hline Distal 2/3 of tibia & Latissimus dorsi & 2 \\
\hline Distal tibia & Gracilis & 1 \\
\hline Heel & Gracilis & 1 \\
\hline Achilles' tendon & Serratus anterior & 1 \\
\hline Lateral malleolus & Gracilis & 1 \\
\hline Dorsal foot & Gracilis & 2 \\
\hline & Gracilis & 1 \\
\hline Plantar foot & Latissimus dorsi & 1 \\
& Gracilis & 1 \\
\hline & Latissimus dorsi & 1
\end{tabular}

\section{Discussion}

In this retrospective study, lower extremity reconstruction with local flaps and free tissue transfer was assessed. Patients with complex lower extremity defects due to traumatic and non-traumatic etiologies were included in this analysis. Overall, the most common etiology was lower extremity trauma in approximately one third of patients. Peripheral vascular disease and diabetes were the following most common causes of distal lower extremity defects. These patient characteristics are representative of the spectrum of comorbidities described for complex lower extremity reconstructions in previous studies $[1,5,12]$.

Flap selection is driven by a multitude of factors. The defect size, anatomical location, and exposed vital structures are crucial in determining the reconstructive concept and flap design. In this study, distal lower extremity defects were included, as proximal defects in the thigh region are often closed primarily or with locoregional reconstruction due to the abundance of soft tissue [2]. The focus on the distal lower extremity has been implemented in comparable studies in the literature [1, 2].

The most common defect locations included in this study were the plantar surface of the foot, the lateral malleolus, and the proximal tibia. The specific tissue properties of the reconstructed location are to be considered, as the anatomical subunits of the distal lower extremity vary greatly in terms of weight-bearing function, skin thickness, and soft tissue contour. Subunit reconstruction for defects in the foot and ankle region was described to achieve both optimal functional and aesthetic results [13]. The reconstruction algorithm to cover complex defects involving the calf and tibia included the division into proximal, middle, and distal thirds [1]. Depending on the size of the defect, the proximal third and knee region can be covered with a gastrocnemius muscle flap with split-thickness skin grafts [14]. Pedicled soleus and gastrocnemius muscle flaps are also reconstructive options for the middle third of the calf [1]. Traditionally, free tissue transfer was most commonly indicated for complex defects of
Table 6 Postoperative complications by flap type

\begin{tabular}{lllll} 
Postoperative complications & Local (\%) & Free (\%) & Total (\%) \\
\hline Delayed wound healing & $4(19 \%)$ & $2(15 \%)$ & $6(17.6 \%)$ \\
\hline Partial flap necrosis & $1(4.8 \%)$ & $1(7.7 \%)$ & $2(5.8 \%)$ \\
\hline Wound dehiscence & $1(4.8 \%)$ & 0 & $1(2.9 \%)$ \\
\hline Flap necrosis & 0 & $1(7.7 \%)$ & $1(2.9 \%)$ \\
\hline Hematoma & $1(4.8 \%)$ & 0 & $1(2.9 \%)$ \\
\hline None & $14(66.7 \%)$ & $9(69.2 \%)$ & $23(67.6 \%)$ \\
\hline Total & 21 & 13 & 34
\end{tabular}

the distal third of the lower extremity $[1,15]$. However, improvements in microsurgical techniques, risk assessment, and perioperative patient management have increased the variety of defects reconstructed with free flaps in recent years [2]. The detailed understanding of flap perfusion, perforators, and the subsequent design of perforator flaps further improved the reconstructive repertoire, as fasciocutaneous perforator flaps may be used as local flaps to reconstruct "like with like" tissue or as free flaps, while minimizing donor site morbidity [10, 16-19].

Free flap reconstruction enables the coverage of larger wounds and avoids additional local donor site trauma in the distal lower extremity [20]. Free tissue transfer is an integral part of the reconstructive ladder, with improved microsurgical techniques and perioperative patient management rendering it a safe and effective option for lower extremity reconstruction [15]. The most common free flaps used in this study were latissimus dorsi and gracilis muscle flaps, both workhorses in microsurgical practice [15, 20, 21]. Free tissue transfer has proven effective in both traumatic and non-traumatic cases of lower extremity reconstruction [1, 7, 22]. Patient factors, timing of the reconstruction, and the vascularity of the leg, as well as defect characteristics, determine flap selection. In traumatic cases, longer vascular pedicles are often required to place the microvascular anastomoses outside of the zone of injury [1]. Reconstruction with well-vascularized free tissue transfer for lower extremity reconstruction after oncological resection proved safe and effective in patients undergoing postoperative radiation therapy $[6,23]$. Free flap reconstruction has led to advances in limb-sparing resection of tumors of the lower extremities [24]. Flap design and tissue composition are variable due to the defect size and specific requirements of the reconstructed region. Free tissue transfer was even proven to be effective in plantar reconstruction, providing stable weight-bearing soft tissue coverage [25].

Extremity preservation may be achieved with both local and free flap reconstruction [11]. However, distal lower extremity reconstruction remains challenging as it is associated with a relatively high percentage of postoperative complications [12, 26]. Patients presenting with lower extremity defects often suffer from multiple comorbidities, which impact postoperative 

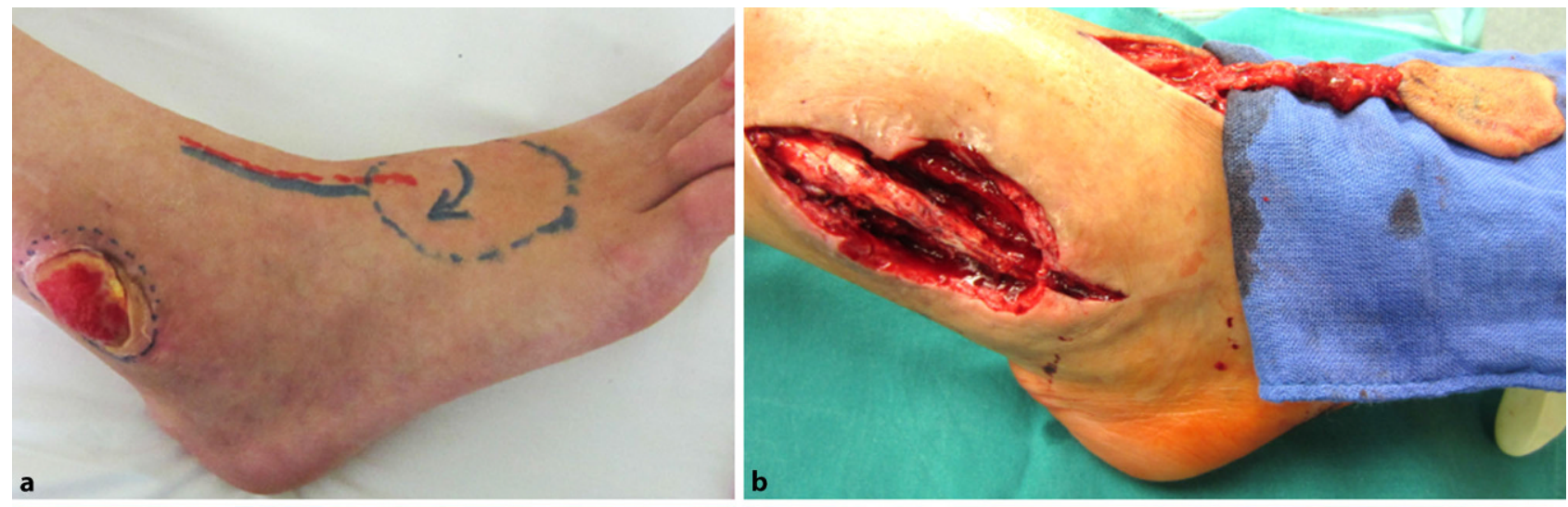

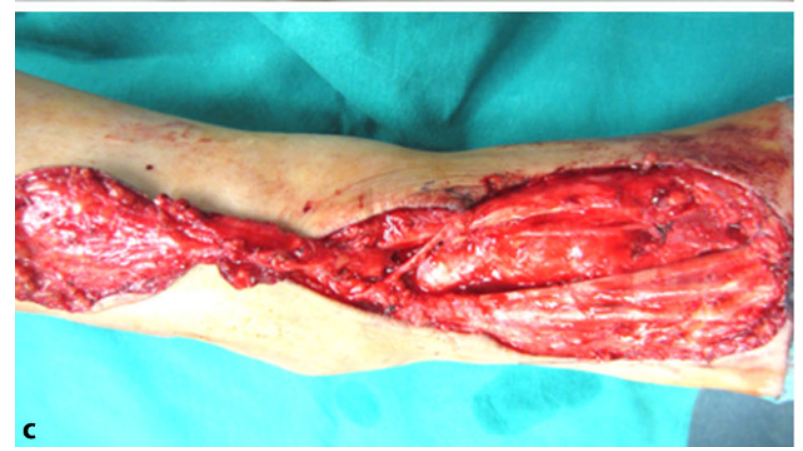

Fig. 1 Local flap reconstruction. Dorsalis pedis flap for lateral malleolus defect with exposed peroneus longus tendon. a Preoperative flap design. b Defect of the lateral malleolus with exposed peroneal muscle tendons after debridement and

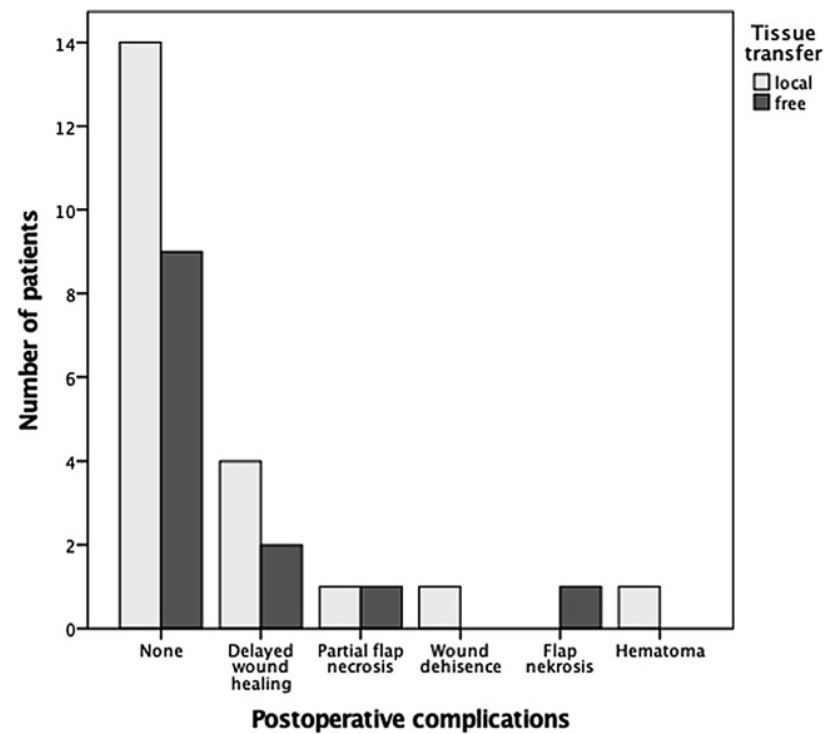

Fig. 2 Postoperative complications. The majority of patients $(n=34)$ did not develop postoperative complications in either the local $(n=21)$ or free flap $(n=13)$ group. The most common complication in both groups was delayed wound healing

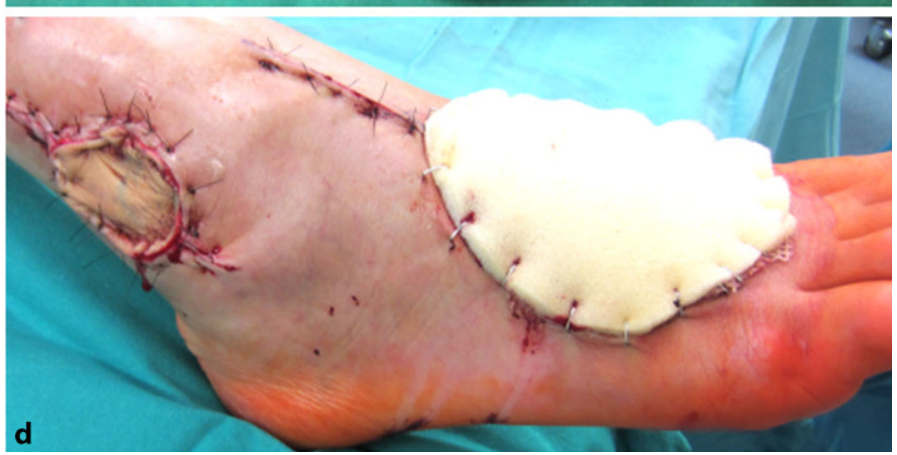

dorsalis pedis flap elevation. The harvest site on the dorsum of the foot (c) was covered with split-thickness skin graft, which was kept in place by tie-over fixation (d)

healing [26-28]. Careful selection of the reconstructive concept to accommodate the patients' functional goals and consider possible risk factors is therefore necessary.

Limitations of the current study are the low case numbers and the retrospective study design. Future prospective investigations should include patients' quality of life and patient-based functional assessments. Age- and gender-specific differences should also be addressed in future studies.

Acknowledgements The authors thank all members of the multidisciplinary team for their contributions in caring for the patients included in this study.

Funding Open access funding provided by Medical University of Vienna.

Conflict of interest E. Györi, A. Fast, A. Resch, T. Rath, and C. Radtke declare that they have no competing interests.

Ethical standards The permission for this retrospective study was given by the institutional ethics committee. Due to the retrospective study design, informed consent could not be obtained from individual included patients. All patients consented to the use of their image materials while undergoing reconstructive surgery.

Open Access This article is licensed under a Creative Commons Attribution 4.0 International License, which permits use, sharing, adaptation, distribution and reproduction in any medium or format, as long as you give appropriate credit to the original author(s) and the source, provide a link to 
the Creative Commons licence, and indicate if changes were made. The images or other third party material in this article are included in the article's Creative Commons licence, unless indicated otherwise in a credit line to the material. If material is not included in the article's Creative Commons licence and your intended use is not permitted by statutory regulation or exceeds the permitted use, you will need to obtain permission directly from the copyright holder. To view a copy of this licence, visit http://creativecommons.org/licenses/by/4.0/.

\section{References}

1. Soltanian H, Garcia RM, Hollenbeck ST. Current concepts in lower extremity reconstruction. Plast Reconstr Surg. 2015;136(6):815e-29e.

2. Fischer JP, Wink JD, Nelson JA, Cleveland E, Grover R, Wu LC, et al. A retrospective review of outcomes and flap selection in free tissue transfers for complexlower extremity reconstruction. J Reconstr Microsurg. 2013;29(6):407-16.

3. Parrett BM, Talbot SG, Pribaz JJ, Lee BT. A review of local and regional flaps for distal leg reconstruction. J Reconstr Microsurg. 2009;25(7):445-55.

4. Xiong L, Gazyakan E, Wahmann M, Bigdeli A, Kremer T, Harhaus L, et al. Microsurgical reconstruction for posttraumatic defects of lower leg in the elderly: A comparative study. Injury. 2016;47(11):2558-64.

5. Xiong L, Gazyakan E, Kremer T, Hernekamp FJ, Harhaus L, Saint-Cyr M, et al. Free flaps for reconstruction of soft tissue defectsinlower extremity: ameta-analysis on microsurgical outcome and safety. Microsurgery. 2016;36(6):511-24.

6. Radtke C, Panzica M, Dastagir K, Krettek C, Vogt PM. Soft tissue coverage of the lower limb following oncological surgery. Front Oncol. 2015;5:303.

7. Lee ZH, Stranix JT, Rifkin WJ, Daar DA, Anzai L, Ceradini DJ, et al. Timing of microsurgical reconstruction in lower extremity trauma: an update of the Godina paradigm. Plast Reconstr Surg. 2019;144(3):759-67.

8. Kristensen MT, Holm G, Kirketerp-Moller K, Krasheninnikoff M, Gebuhr P. Very low survival rates after non-traumatic lower limb amputation in a consecutive series: what to do? Interact CardioVasc Thorac Surg. 2012;14(5):543-7.

9. Ducic I, Hung V, Dellon AL. Innervated free flaps for foot reconstruction: a review. J Reconstr Microsurg. 2006;22(6):433-42.

10. Gir P, Cheng A, Oni G, Mojallal A, Saint-Cyr M. Pedicledperforator (propeller) flaps in lower extremity defects: a systematic review. J Reconstr Microsurg. 2012;28(9):595-601.

11. Kozak GM, Hsu JY, Broach RB, Shakir S, Calvert C, Stranix JT, et al. Comparative effectiveness analysis of complex lower extremity reconstruction: outcomes and costs for biologically based, local tissue rearrangement, and free flap reconstruction. Plast ReconstrSurg. 2020;145(3):608e-16e.

12. Baumeister SP, Spierer R, Erdmann D, Sweis R, Levin LS, Germann GK. A realistic complication analysis of 70 sural artery flaps in a multimorbid patient group. Plast Reconstr Surg. 2003;112(1):129-40. discussion 41-2.

13. Hollenbeck ST, Woo S, Komatsu I, Erdmann D, Zenn MR, Levin LS. Longitudinal outcomes and application of the subunit principle to 165 foot and ankle free tissue transfers. Plast Reconstr Surg. 2010;125(3):924-34.

14. Daigeler A, Drucke D, Tatar K, Homann HH, Goertz O, Tilkorn D, et al. The pedicled gastrocnemius muscle flap: a review of 218 cases. Plast Reconstr Surg. 2009;123(1):250-7.

15. Heller L, Levin LS. Lower extremity microsurgical reconstruction. Plast Reconstr Surg. 2001;108(4):1029-41. quiz 42.

16. Saint-Cyr M, Schaverien MV, Rohrich RJ. Perforator flaps: history, controversies, physiology, anatomy, and use in reconstruction. Plast Reconstr Surg. 2009;123(4):132e-45e.

17. Koshima I, Narushima M, Mihara M, Nakai I, Akazawa S, Fukuda N, et al. Island medial plantar artery perforator flap for reconstruction of plantar defects. Ann Plast Surg. 2007;59(5):558-62.

18. Kim ES, Hwang JH, Kim KS, Lee SY. Plantar reconstruction using the medial sural artery perforator free flap. Ann Plast Surg. 2009;62(6):679-84.

19. Mohan AT, Sur YJ, Zhu L, Morsy M, Wu PS, Moran SL, et al. The concepts of propeller, perforator, keystone, and other local flaps and their role in the evolution of reconstruction. Plast Reconstr Surg. 2016;138(4):710e-29e.

20. Saint-Cyr M, Wong C, Buchel EW, Colohan S, Pederson WC. Free tissue transfers and replantation. Plast Reconstr Surg. 2012;130(6):858e-78e.

21. PedersonWC, Grome L. Microsurgical reconstruction of the lower extremity. Semin Plast Surg. 2019;33(1):54-8.

22. Egeler SA, de Jong T, Luijsterburg AJM, Mureau MAM. Long-term patient-reported outcomes following free flap lower extremity reconstruction for traumatic injuries. Plast Reconstr Surg. 2018;141(3):773-83.

23. Suh HS, Lee JS, Hong JP. Consideration in lower extremity reconstruction following oncologic surgery: patient selection, surgical techniques, and outcomes. J Surg Oncol. 2016;113(8):955-61.

24. Heller L, Kronowitz SJ. Lower extremity reconstruction. JSurg Oncol. 2006;94(6):479-89.

25. Heidekrueger PI, Ehrl D, Prantl L, Thiha A, Weinschenk F, Forte AJ, et al. Microsurgical reconstruction of the plantar foot: long-term functional outcomes and quality of life. JReconstr Microsurg. 2019;35(5):379-88.

26. Bigdeli AK, Gazyakan E, Schmidt VJ, Bauer C, Germann G, Radu CA, et al. Long-term outcome after successful lower extremity free flap salvage. J Reconstr Microsurg. 2019;35(4):263-9.

27. Rainer C, Schwabegger AH, Meirer R, Perkmann R, Ninkovic M, Ninkovic M. Microsurgical management of the diabeticfoot. J Reconstr Microsurg. 2003;19(8):543-53.

28. Qian Y, Li G, Zang H, Cao S, Liu Y, Yang K, et al. A systematic review and meta-analysis of free-style flaps: risk analysis of complications. Plast Reconstr Surg Glob Open. 2018;6(2):e1651.

Publisher's Note Springer Nature remains neutral with regard to jurisdictional claims in published maps and institutional affiliations. 